\title{
Histological survey of the saphenous vein before its use as autologous aortocoronary bypass graft
}

\author{
GAETANO THIENE, PAOLO MIAZZI, MARCO VALSECCHI, MARIALUISA VALENTE, \\ UBERTO BORTOLOTTI, DINO CASAROTTO, AND VINCENZO GALLUCCI
}

From the Departments of Pathology and Cardiovascular Surgery, University of Padova Medical School, Padova, Italy

\begin{abstract}
A histological examination has been carried out on the saphenous veins used in 150 consecutive patients undergoing aortocoronary bypass. Morphological changes were observed frequently and consisted mainly of fibrosis of the intima and of the medial longitudinal muscular layer. Intimal fibrosis was rarely severe enough to narrow the lumen significantly. Statistical analysis disclosed that the fibrosis of the intima and of the medial longitudinal muscular layer do not increase with age. The use of frozen histological sections of the saphenous vein in patients undergoing aortocoronary bypass operations could be considered in order to discard unsuitable grafts and to direct the surgeon to alternative conduits.
\end{abstract}

The widespread use of autologous saphenous vein for direct myocardial revascularisation procedures is attributable mainly to its easy and safe surgical removal, its almost ideal size and versatility, and its biological acceptance.

While the pathological changes occurring in saphenous vein grafts have been extensively studied, ${ }^{1-12}$ very little attention has been paid to the condition of the vein before operation, and the proliferative lesions, observed even early after surgery, have usually been regarded as acquired.

In order to verify the condition of the venous wall before its use as an aortocoronary conduit and to evaluate possible pre-existing morphological changes, a histological survey has been carried out on samples of the same autologous saphenous veins used for the bypass.

\section{Methods}

The saphenous vein is removed routinely according to the following technique. The surgeon isolates a segment of vein between the ankle and the knee from one or both legs, through a single incision. Particular care is taken to avoid dissection of the adventitia as well as any trauma to the venous wall and to the saphenous nerve. After all the collateral vessels have been ligated, the vein is removed, washed with heparinised saline,

Address for reprint requests: Dr Gaetano Thiene. Istituto di Anatomia e Istologia Patologica, Via Gabelli 61, 35100 Padova. Italy. and briefly stored in it until use.

A histological examination was performed on the same saphenous veins used in 150 consecutive patients undergoing aortocoronary bypass. The patients have been divided into four groups according to age: 21 patients with ages ranging from 35 to 44 years (group A); 76 patients ranging from 45 to 54 years (group B); 45 patients ranging from 55 to 64 years (group C); and eight patients aged more than 65 years (group D).

Multiple segments of the veins were embedded in paraffin and sections of 10 micron thickness were stained with haematoxylin-eosin, WeigertVan Gieson, and PAS.

\section{Histology of normal saphenous vein}

The wall of the human saphenous vein contains a thin intima, separated from the media by a rudimentary internal elastic membrane. The media consists of two distinct layers of muscle cells: an internal longitudinal layer mixed with bundles of collagen and an external circular layer. The adventitia is composed mainly of bundles of collagen with scattered longitudinal fascicles of smooth muscular cells. Near the insertion of the venous valves the longitudinal muscular layer usually becomes thicker.

\section{Results}

The main pathological findings consisted of 


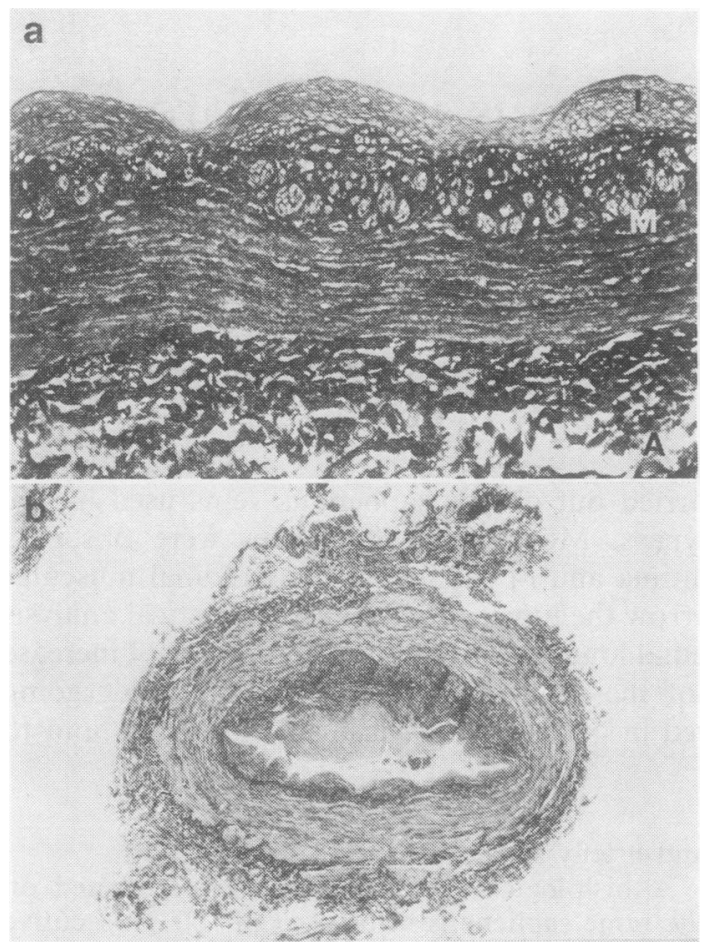

Fig 1 (a) Saphenous vein wall with grade 1 intimal proliferation and grade 2 sclerosis of the medial muscular longitudinal layer. I=intima; $M=$ media; $A=$ adventitia. Elastic-Van Gieson stain, original magnification $\times 64$. (b) Saphenous vein with grade 3 intimal proliferation. Elastic-Van Gieson stain, original magnification $\times 18$.

various degrees of intimal fibrous thickening, sclerosis of the medial longitudinal muscular layer, and elastosis of the internal elastic lamina (fig 1).

The sclerosis of the inner medial layer, which appears as a replacement process of the muscle elements, has been graded as minimal (grade 1), mild (grade 2), moderate (grade 3), and severe (grade 4).

The intimal fibrosis consisted of an acellular connective tissue proliferation, causing luminal narrowing; it has been classified as grade 1 (focal proliferation with minimal narrowing), grade 2 (concentric proliferation with mild narrowing), grade 3 (concentric proliferation with moderate narrowing-less than $50 \%$ of the lumen), and grade 4 (marked narrowing-more than $50 \%$ of the lumen).

Only 10 out of 150 veins $(6.6 \%)$ were free from lesions. One hundred and five $(70 \%)$ showed intimal fibrosis: grade 1 in $70(66.6 \%)$, grade 2 in

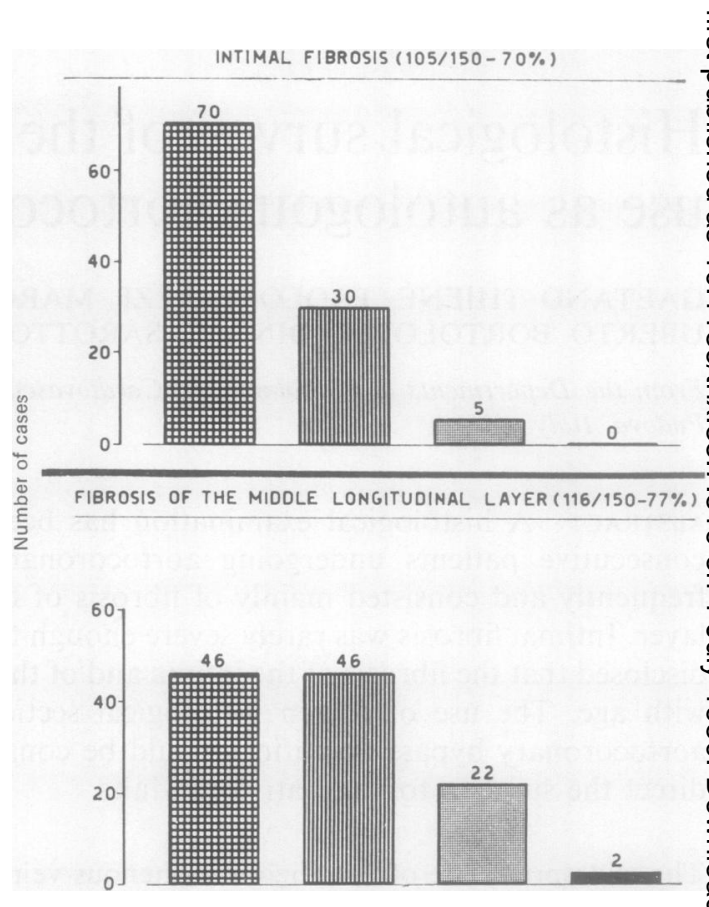

Fig 2 Pattern of distribution of the fibrosis observed $\stackrel{\mathbb{Q}}{\triangle}$ in the intima and the middle longitudinal layer of $150 \overrightarrow{\vec{B}}$ saphenous veins, according to grade of lesion-

$\square=$ grade 4 , 国 = grade 3 , $\mathbf{m}=$ grade 2 ,

= grade 1 .

$30(28.7 \%)$, and grade 3 in five $(4 \cdot 7 \%$ ) (fig 2). No patients exhibited a grade 4 intimal fibrosis.

Sclerosis of the medial longitudinal muscularx layer was present in 116 out of 150 specimenso $(77 \%)$ : grade 1 in $46(39.6 \%)$, grade 2 in 46. $(39.6 \%)$, grade 3 in $22(19 \%)$, and grade 4 in two $(1.7 \%)$ (fig 2). Figure 3 shows the distribution of the lesions in the four age groups.

The comparison of the intimal fibrosis in groups $\mathrm{A}$ and $\mathrm{C}$, between grades 0 and 3 , showed no statistical significance $\left(x^{2}=0.03\right.$ and 0.04 re- N spectively, $\mathrm{p}<0 \cdot 5$ ).

Furthermore, the comparison of the fibrosis of the longitudinal muscular layer in groups $\mathbf{A}$ andw $C$, between grades 0 and 3 , revealed no significant increment with age $\left(\chi^{2}=2.47\right.$ and 0.18 , respece tively, $\mathrm{p}<0.5$ ).

\section{Discussion}

The results of our histological investigation shows that morphological changes were present almos constantly in the walls of the fresh "normal"? saphenous veins before their use as aortocoronary conduits. 

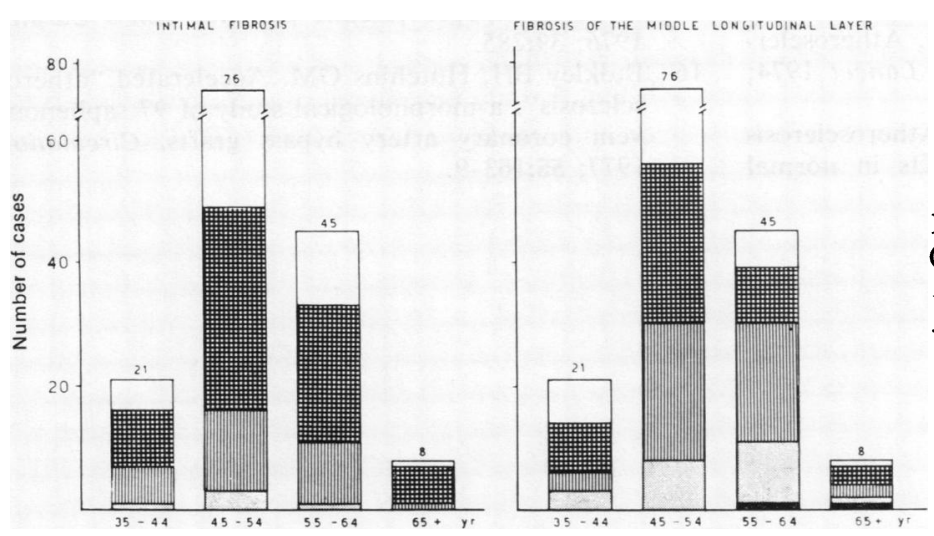

Fig 3 The five degrees of lesion (grades as in fig 2, $\square=$ grade 0 ) in the 150 saphenous veins, distributed in four age groups.
The main pathological findings consisted of intimal fibrosis, while in the media only the longitudinal muscular layer was involved by the sclerotic process. Although these lesions are usually regarded as an aging process, our statistical analysis revealed that neither the intimal nor the medial sclerosis was correlated with the age of the patients.

The intimal fibrosis was rarely so severe as to reduce significantly the lumen of the vein (five cases with lumen narrowed more than $25 \%$ ). Nevertheless the condition of the vein should be carefully assessed in each instance in order to discard unsuitable grafts and to direct the surgeon to alternative conduits. In case of doubt, frozen section examination should be considered.

Early and long-term saphenous vein patency depends upon various factors, such as systemic arterial pressure, ${ }^{4}$ distal coronary circulation, ${ }^{11}$ mural vein ischaemia, ${ }^{13}$ and graft involvement by progressive atherosclerosis. ${ }^{14-16}$ The intimal and medial fibrosis observed in the saphenous veins before their use might contribute to the development of progressive proliferation, leading to late graft occlusion.

The pathogenetic importance of this factor will be studied by comparing these histological data with the results of long-term coronary arteriography in these groups of patients, and possibly with specimens removed at reoperation or recovered at necropsy.

\section{References}

1 Grondin CM, Meere C, Castonguay Y, Lepage G, Grondin P. Progressive and late obstruction of an aortocoronary venous bypass graft. Circulation 1971; 43:698-702.

2 Johnson WD, Auer JE, Tector AJ. Late changes in coronary vein grafts. $A m J$ Cardiol 1970; 26: 640.

3 Marti MC, Bouchardy B, Cox JN. Aortocoronary artery bypass grafts with autogenous saphenous vein grafts: histopathological aspects. Virchows Archiv (Pathol Pat Anat) 1971; 352:255-66.

4 Vlodaver Z, Edwards JE. Pathologic changes in aortic-coronary arterial saphenous vein grafts. Circulation 1971; 44:719-28.

5 Brody WR, Angell WW, Kosek JC. Histologic fate of the venous coronary artery bypass in dogs. Am J Pathol 1972; 66:111-9.

6 Kern WH, Dermer GB, Lindesmith GG. The intimal proliferation in aortic coronary saphenous vein grafts: light and electron microscopic studies. Am Heart J 1972; 84:771-7.

7 Vlodaver Z, Edwards JE. Pathologic analysis in fatal cases following saphenous vein coronary arterial bypass. Chest 1973; 64:555-63.

8 Unni KK, Kottke BA, Titus JL, Fryer RL, Wallace RB, Brown AL. Pathologic changes in aortocoronary saphenous vein grafts. $A m$ J Cardiol 1974; 34:526-31.

9 Barboriak JJ, Batayias GE, Pintar K, Korns ME. Pathological changes in surgically removed aorto-coronary vein grafts. Ann Thorac Surg 1976; 21:524-7.

10 Lawrie GM, Lie JT, Morris GC, Beazley HL. Vein graft patency and intimal proliferation after aorto-coronary bypass: early and long-term angiopathologic correlations. Am J Cardiol 1976; 38: 856-62.

11 Spray TL, Roberts WC. Changes in saphenous veins used as aortocoronary bypass grafts. $\mathrm{Am}$ Heart J 1977; 94:500-16.

12 Thiene G, Gallucci V, Miazzi P, Casarotto D. Pathology of the saphenous vein graft in aortocoronary bypass: pathologic observations. XII Congress of the International Academy of Pathology, Jerusalem, 10-15 September 1978 (abstr).

13 Brody WR, Kosek JC, Angell WW. Changes in vein grafts following aorto-coronary bypass induced by pressure and ischemia. J Thorac 
Cardiovasc Surg 1972; 64:847-54.

14 Barboriak JJ, Pintar K, Korns ME, Atherosclerosis in aorto-coronary vein grafts. Lancet 1974; 2:621-4.

15 Lie JT, Lawrie GM, Morris GC. Atherosclerosis of aorto-coronary bypass vein grafts in normal and hyperlipoproteinemic patients. Am J Cardiol 1976; 39:285.

16 Bulkley BH, Hutchins GM. Accelerated "atherosclerosis": a morphological study of 97 saphenous vein coronary artery bypass grafts. Circulation 1977; 55:163-9. 